\title{
Functional Neuroanatomy of Human Slow Wave Sleep
}

\author{
Pierre Maquet, ${ }^{1,2}$ Christian Degueldre, ${ }^{1}$ Guy Delfiore, ${ }^{1}$ Joël Aerts, ${ }^{1}$ Jean-Marie Péters, ${ }^{1}$ André Luxen, ${ }^{1}$ and \\ Georges Franck ${ }^{1,2}$ \\ ${ }^{1}$ Cyclotron Research Center, University of Liège, 4000 Liège, Belgium, and ${ }^{2}$ Department of Neurology, Centre Hospitalier \\ Universitaire Liège, Belgium
}

The distribution of regional cerebral blood flow (rCBF) was estimated during sleep and wakefulness by using $\mathrm{H}_{2}{ }^{15} \mathrm{O}$ positron emission tomography (PET) and statistical parametric mapping. A group analysis on 11 good sleepers (8 with steady slow wave sleep, SWS) showed a significant negative correlation between the occurrence of SWS and rCBF in dorsal pons and mesencephalon, thalami, basal ganglia, basal forebrain/ hypothalamus, orbitofrontal cortex, anterior cingulate cortex, precuneus, and, on the right side, in a region that follows the medial aspect of the temporal lobe. Given the known decrease in global cerebral blood flow levels during SWS, these negative correlations suggest that rCBF is decreased significantly more in these cerebral areas than in the rest of the brain.

The marked rCBF decreases in the pons, mesencephalon, thalamic nuclei, and basal forebrain reflect their close implica- tion in the generation of SWS rhythms. The influence of these rhythms on the telencephalon usually are thought to be global and homogeneous. In contrast, our results show that rCBF is decreased more in some cortical areas (especially in orbitofrontal cortex) than in the rest of the cortex. We hypothesize that cellular processes taking place during SWS might be modulated differently in these regions.

Given the functions of the ventromedial frontal areas, we surmise that SWS might be particularly critical for the adaptation of behavior to environmental pressures. This hypothesis is supported indirectly by results of sleep deprivation experiments.

Key words: slow wave sleep; cerebral blood flow; sleep deprivation; REM sleep; positron emission tomography; statistical parametric mapping; cerebral function
Processes taking place during sleep undoubtedly provide a considerable survival advantage to a wide range of animal species and, in particular, to mammals (Meddis, 1983). This is probably the reason why sleep is observed so widely in the animal kingdom. Even in species in which sleep may endanger the individuals, the process is maintained. This sometimes necessitates an adaptation in its architecture (e.g., cetaceans; Mukhametov et al., 1988).

Sleep thus seems to be one of the last complex integrated behaviors for which the adaptive advantage remains unknown. There is, however, no shortage of theories explaining the functions of sleep: energy conservation/protection against energetic exhaustion (Berger and Philipps, 1995), thermoregulation (McGinty and Szymusiak, 1990), adaptation to an ecological niche (Webb, 1974), “instinctual behavior” (Meddis, 1977), restoration of tissular integrity (Adam, 1980), neuronal plasticity (Krueger et al., 1995), processing of memory traces (Giuditta, 1985; Smith, 1995), etc. The situation becomes more complicated because of the presence, in homeotherms, of two types of sleep (slow wave sleep, SWS, and rapid eye movement sleep, REMS), which may (or may not) have different and independent functions. In hu-

\footnotetext{
Received Nov. 15, 1996; revised Jan. 30, 1997; accepted Feb. 6, 1997.

P.M. is Research Associate at the Fonds National de la Recherche Scientifique de Belgique (FNRS). This research was supported by FNRS Grant (3.4547.93), by the Fonds Spéciaux de la Recherche of the University of Liège, by the European Sleep Research Society-Synthélabo Research Grant 1994, and by the Queen Elizabeth Medical Foundation. We are greatly indebted to Professor R. S. J. Frackowiak and Dr. K. J. Friston (Wellcome Department of Cognitive Neurology, Institute of Neurology, London, UK) for kindly having provided the statistical parametric mapping software, to Dr. G. Hartstein for checking the language, to Patrick Hawotte and Marcel Piérrard for their (nocturnal) technical assistance, and to Dr. Sonia Fuchs and Ms. Valérie Delvaux for their participation in subject selection.

Correspondence should be addressed to Dr. Pierre Maquet, Cyclotron Research Center (B 30), University of Liège, 4000 Liège, Belgium.

Copyright (C) 1997 Society for Neuroscience $0270-6474 / 97 / 172807-06 \$ 05.00 / 0$
}

mans, SWS is divided further into light (stage 2) and deep (stages 3 and 4) SWS. In this paper, SWS refers to human deep SWS.

It generally is accepted that the cellular processes taking place during sleep benefit the CNS. At the very least, it is in the brain that the cellular function is modified most dramatically by periods of sleep. An increasing body of data describes the modes of neuronal discharge that, during the various sleep phases, lead to the generation and maintenance of SWS and REMS (Steriade and McCarley, 1990). The global variations of energy metabolism that ensue also have been described (Maquet, 1995). Much less is known about the distribution of cerebral activity during sleep, especially within the cortex. Are the modifications of neuronal activity homogeneously distributed throughout the encephalon during sleep or are some areas more affected than others? A better description of the distribution of brain activity during sleep might provide clues for a better understanding of sleep phenomena and thereby constitute an approach to the analysis of the function(s) of sleep.

In this exploratory study, using positron emission tomography (PET), we estimated regional cerebral blood flow (rCBF) as a marker of neuronal activity and determined its regional distribution during sleep in man. The interpretation of our results is tentative. Neuroimaging studies usually localize the neural networks involved in a particular cognitive task specifically explored by the experimental design. On the contrary, in our case, the distribution of regional activity was generated only by the cellular processes taking place during physiological sleep and was disturbed as little as possible by the experimental procedure. From the localization of the areas for which the rCBF changed significantly and from what is known of the function of these areas during wakefulness, we hoped to determine precisely which of the 
cerebral functions might be related to, and benefit from, SWS in humans.

Preliminary results of the present experiment already have been published in abstract form (Maquet et al., 1995).

\section{MATERIALS AND METHODS}

Subjects' selection. This study was approved by the Ethics Committee of the University of Liège. Young (20-30 year) male subjects were considered for selection after they had given written informed consent. They completed a questionnaire concerning their general state of health and sleep habits. None had significant medical, surgical, or psychiatric illness. None were on medication, took illicit drugs, or regularly drank alcohol. All were strongly right-handed by the Edinburgh Inventory (Oldfield, 1971). The experiment was run on three separate nights, at 1 week intervals, during which the subjects were required to sleep on the scanner couch during polygraphic monitoring. A standard sleep montage was used, which included EEG (C3-A2 and C4-A1), horizontal electrooculogram, and chin EMG recordings. Polysomnographic recordings were scored visually with the Rechtschaffen and Kales criteria (1968). In this paper SWS refers specifically to deep stages of sleep (stages 3 and 4 SWS). The first two test nights were used for subject selection. During the first test night the subject was allowed to sleep under conditions close to normal. The second night was spent under conditions closer to the experimental situation (limitation of head and left arm mobility). To ensure optimal sleep stability in this difficult condition, we asked the subjects not to sleep the night before the second (and, when appropriate, the third) test sessions.

Subjects who maintained two periods of SWS and REMS of at least 20 min each during each of the first two test nights were selected for the final night of testing.

Behavioral paradigm. At the beginning of the third night the polysomnographic electrodes were placed, and a cannula was inserted in a left antebrachial vein. To reduce movements during sleep, we secured the subject's head to the scanner head holder with a thermoplastic face mask (Truscan Imaging, Annapolis, MD), while we strapped the left forearm to a sand bag. During the night six PET scans were performed in total darkness, scheduled in the following order: waking (W), SWS, SWS, REMS, REMS, W. This order was imposed by the physiological preponderance of SWS early in the night and of REMS in the early morning. During sleep the scans were performed when polysomnography showed characteristic sleep patterns (SWS or REMS) that remained clear-cut during the $5 \mathrm{~min}$ period necessary for production of radiolabeled water. Immediately after each sleep scan the subjects were awakened and asked to describe what they had in their minds.

PET acquisitions. Subjects were positioned $15 \mathrm{~mm}$ above the canthomeatal line. A transmission scan was performed to allow a measured attenuation correction. Each of the six emission scans consisted of two frames: a $60 \mathrm{sec}$ background frame and a $120 \mathrm{sec}$ frame. The slow intravenous water $\left(\mathrm{H}_{2}{ }^{15} \mathrm{O}\right)$ infusion began just before the second frame to observe the head curve rising within the first $10 \mathrm{sec}$ of this frame. Thirty millicuries $(1110 \mathrm{MBq})$ were injected for each scan, in $10 \mathrm{cc}$ of saline, over a period of $60 \mathrm{sec}$. The infusion was automated totally so as not to awaken the subject during the scanning periods.

Data were acquired by a Siemens CTI 951 R 16/31 scanner in twodimensional mode. Data were reconstructed with the use of a Hanning filter (cut-off frequency, 0.5 cycle/pixel) and corrected for attenuation and background activity [final in-plane image resolution, full-width, halfmaximum (FWHM): $8.7 \mathrm{~mm}$ (Degueldre and Quaglia, 1992)].

Data analysis. PET data were analyzed with the statistical parametric mapping (SPM) software (SPM95 version; Wellcome Department of Cognitive Neurology, Institute of Neurology, London, UK; Frackowiak and Friston, 1994) implemented in MATLAB (Mathworks, Sherborn, MA). Briefly, data from each subject were realigned by using a leastsquares approach with the first scan as a reference (Friston et al., 1995a). After realignment all images were transformed into a standard space (Talairach and Tournoux, 1988; Friston et al., 1995a) and then smoothed with a $12 \mathrm{~mm}$ FWHM isotropic kernel. A design matrix was specified according to the general linear model (Friston et al., 1991a, 1994, 1995b). This included the global activity as a confounding covariant (Friston et al., 1990). The condition and subject effects first were estimated at each and every voxel. The analysis used linear contrasts to identify brain regions where $\mathrm{rCBF}$ significantly correlated with the presence of one particular functional state (i.e., W, SWS, or REMS). The resulting set of voxel values for each contrast constituted a map of the $t$ statistic
$(\operatorname{SPM}\{t\})$. Then the SPM $\{t\}$ was transformed to the unit normal distribution (SPM $\{Z\})$ and thresholded at $p<0.001(Z=3.09)$. The resulting foci of activation were characterized, finally, in terms of peak height over the entire volume analyzed [i.e., the probability that the rCBF variation could have occurred by chance, $\left.p_{(Z \max }>\mathrm{u}\right)$; this corresponded to a corrected $p$ value $<0.05]$. We particularly were interested to explore negative correlations with SWS, which localize the brain areas where rCBF is most decreased in deep SWS (see Discussion).

\section{RESULTS}

Thirty young (mean age, 22.5 years; range, 20-25 years) subjects volunteered for the study. Nineteen fulfilled the selection criteria and were scanned. From this population four subjects were studied for a complete set of states (2 W, 2 SWS, 2 REMS); another group of three was scanned during two $\mathrm{W}$ and two REMS but changed their sleep stage during the SWS injections. A final group of four subjects was scanned during two W and two SWS but changed their sleep stage during the REMS injections. The analysis was performed with these three groups (11 subjects in total, 8 subjects with stable SWS). Results concerning the REMS data have been published previously (Maquet et al., 1996).

Negative correlations with SWS were observed in three cerebral areas (Table 1, Fig. 1). The first was located in the anterior cingulate cortex (BA 24-BA 32) and the second in the precuneus (BA 7) and upper part of the cuneus (BA 19). The third area encompassed the tegmentum of the pons and of the mesencephalon, both thalami, the basal ganglia (left caudate and both lenticular nuclei), the basal forebrain/hypothalamus, and the orbital frontal cortex (BA 11 and BA 25). On the right side, between the mesencephalon and the basal ganglia, a strip of activation skirted the ventral edge of the brainstem and diencephalon, closely following the medial aspect of the right temporal lobe: parahippocampal gyrus, entorhinal cortex, and amygdaloid complex. This area excluded the hippocampus proper. A local maximum was observed in this area, the coordinates of which correspond to the anterior part of the entorhinal cortex. On the left side, the activation focus of the basal ganglia spread downward toward the amygdaloid complex as well. No local maxima were located in the amygdaloid complexes on either side.

\section{DISCUSSION}

\section{Modifications of global flow during SWS}

Except in an early report (Mangold et al., 1955) that has been critically reviewed (Kennedy et al., 1980), a significant decrease in CBF invariably was observed during SWS, as compared with W levels (Townsend et al., 1973; Sakai et al., 1980; Madsen et al., 1991). The present study was not aimed at describing these global modifications of cerebral blood flow (CBF) during sleep but explored the regional distribution of $\mathrm{CBF}$. However, it should be remembered that, because global CBF decreases during SWS, the regions where $\mathrm{rCBF}$ is negatively correlated with SWS are precisely the areas where $\mathrm{rCBF}$ is most decreased.

For practical reasons we used integrated tomographic counts instead of parametric CBF images. This was unlikely to have modified our results as long as focal-and not global-blood flow variations were investigated (Fox and Mintun, 1989; Ingvar et al., 1994). Modifications of global flow were taken into account by statistical parametric mapping, which included an ANCOVA, using global flow as confounding covariant. Among other image intensity normalization methods, ANCOVA was shown to be the most conservative (Arndt et al., 1996). 
Table 1. Localization ${ }^{a}$ and statistical results ${ }^{b}$ concerning local maxima of the brain areas where rCBF is negatively correlated with SWS

\begin{tabular}{|c|c|c|c|c|c|c|}
\hline Area (Brodmann's area) & & $x$ & $y$ & $z$ & $Z$ score & $p$ (corrected) \\
\hline \multirow[t]{5}{*}{ Orbital frontal cortex } & $(11)$ & 8 & 46 & -16 & 5.59 & $<0.001$ \\
\hline & & 10 & 32 & -20 & 4.48 & 0.010 \\
\hline & & -2 & 52 & -12 & 4.22 & 0.026 \\
\hline & $(25)$ & -14 & 4 & -12 & 5.15 & 0.001 \\
\hline & & -2 & 10 & -16 & 4.85 & 0.002 \\
\hline Anterior cingulate cortex & $(24)$ & 0 & 38 & 8 & 4.14 & 0.035 \\
\hline \multirow[t]{2}{*}{ Precuneus } & $(19 / 7)$ & -2 & -80 & 36 & 5.11 & 0.001 \\
\hline & & 0 & -66 & 24 & 4.43 & 0.012 \\
\hline Right mesiotemporal cortex & $(28)$ & 16 & -12 & -12 & 5.38 & $<0.001$ \\
\hline Left caudate nucleus & & -10 & 8 & 4 & 4.57 & 0.007 \\
\hline Right lenticular nucleus & & 24 & 8 & 0 & 5.79 & $<0.001$ \\
\hline Left lenticular nucleus & & -20 & -4 & -8 & 5.11 & 0.001 \\
\hline \multirow[t]{2}{*}{ Right thalamus } & & 14 & -24 & 8 & 5.29 & $<0.001$ \\
\hline & & 20 & -14 & 8 & 5.05 & 0.001 \\
\hline Left thalamus & & -8 & -22 & 4 & 5.06 & 0.001 \\
\hline Basal forebrain/hypothalamus & & 2 & 2 & -4 & 4.52 & 0.008 \\
\hline Mesencephalon & & 10 & -22 & -12 & 5.24 & $<0.001$ \\
\hline \multirow[t]{2}{*}{ Pons } & & -8 & -32 & -28 & 4.92 & 0.001 \\
\hline & & 20 & -34 & -24 & 5.21 & $<0.001$ \\
\hline
\end{tabular}

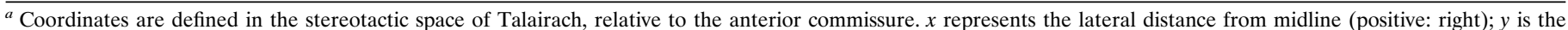
anteroposterior distance from the anterior commissure (positive: anterior); $z$ represents the rostrocaudal distance from the bicommissural plane (positive: rostral).

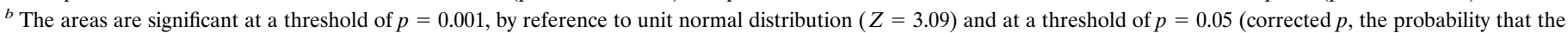
regional rCBF variation could have occurred by chance over the entire volume analyzed).

\section{Deactivation of subcortical structures}

Previous reports already have described important rCBF and glucose metabolism decreases in various subcortical structures during SWS (Buchsbaum et al., 1989; Maquet et al., 1990; Balkin et al., 1991; Braun et al., 1992). Our results more precisely localize these prominent rCBF decreases in central core structures (dorsal pons and mesencephalon, both thalami, and basal ganglia). These subcortical structures are all known to play a permissive role in, or to actively participate in, the generation of slow oscillations during SWS. The only exception is represented by the basal ganglia, for which the relation with the SWS oscillations is less clear.

The negative correlation observed within the dorsal pons and the mesencephalon during SWS reflects the persistent decrease in the firing rate of neurons of diffuse ascending brainstem systems, which leads to the hyperpolarization of thalamic nuclei (Steriade and McCarley, 1990).

At the thalamic level properties of thalamic neurons, as well as of intrathalamic and thalamocortical circuits (Steriade et al., 1990), lead, on the average, to a decrease in energy metabolism and blood flow in thalamic nuclei and explain the negative correlation found in thalamic nuclei. Under conditions of hyperpolarization (reticular and relay) thalamic neurons adopt a bursting pattern of firing characterized by prolonged phases of hyperpolarization that lead to synchronous oscillations of large neuronal thalamic and cortical assemblies within spindle and then delta frequency range (Steriade et al., 1990). The energy required for active inhibition [e.g., that arising in the reticular thalamus (Steriade and McCarley, 1990)] or for spike generation is offset by the decrease in firing rate caused by these long-lasting hyperpolarization periods.

Our results also show significant deactivation of basal forebrain and hypothalamus. The limited spatial resolution of the SPM impedes a thorough discussion concerning these areas, which consist of heterogeneous sets of neuronal structures implicated in the modulation of cortical activation and arousal (Metherate et al., 1992) but also in sleep generation (Szymusiak and McGinty, 1986; Szymusiak, 1995). The observed deactivation might reflect the decrease in CBF related to the bursting pattern that occurs in the largest fraction of basal forebrain neurons (Nunez, 1996) caused by their intrinsic properties (Khateb et al., 1992).

The significant negative correlation observed in the basal ganglia was not expected. These structures are not known to participate in the generation of SWS rhythms. In anesthetized animals long-lasting hyperpolarizing shifts in membrane potential are observed in striatal neurons (Wilson, 1994). They would seem to be attributable to changes in excitatory inputs from afferent thalamic and corticostriatal neurons (Cowan and Wilson, 1994). The significant $\mathrm{rCBF}$ decrease in basal ganglia thus might reflect the significant deactivation of afferent thalamic nuclei and cortical (especially frontal) areas.

\section{Cortical deactivation, with special emphasis on prefrontal cortex deactivation}

Some preliminary PET studies explored the distribution of cortical blood flow during SWS (Balkin et al., 1991; Braun et al., 1992; Hetta et al., 1995). All compared the SWS distribution with the waking state. We preferred to avoid such categorical comparisons, because mental activity occurring during $\mathrm{W}$ is characterized by its own rCBF distribution (Andreasen et al., 1995) that might confound the results. In keeping with these preliminary reports, our results confirmed that the prefrontal $\mathrm{rCBF}$ was depressed more significantly than in other cortical areas during SWS. In contrast to previous studies, only orbital prefrontal cortex seemed to be affected, whereas no significant correlation was found in prefrontal convexity. We also observed a significant negative correlation in anterior cingulate and precuneus, which thus far have not been described. The cause of these discrepancies is perhaps the statistical sensitivity of the methods used and the relatively small size of populations heretofore reported. 


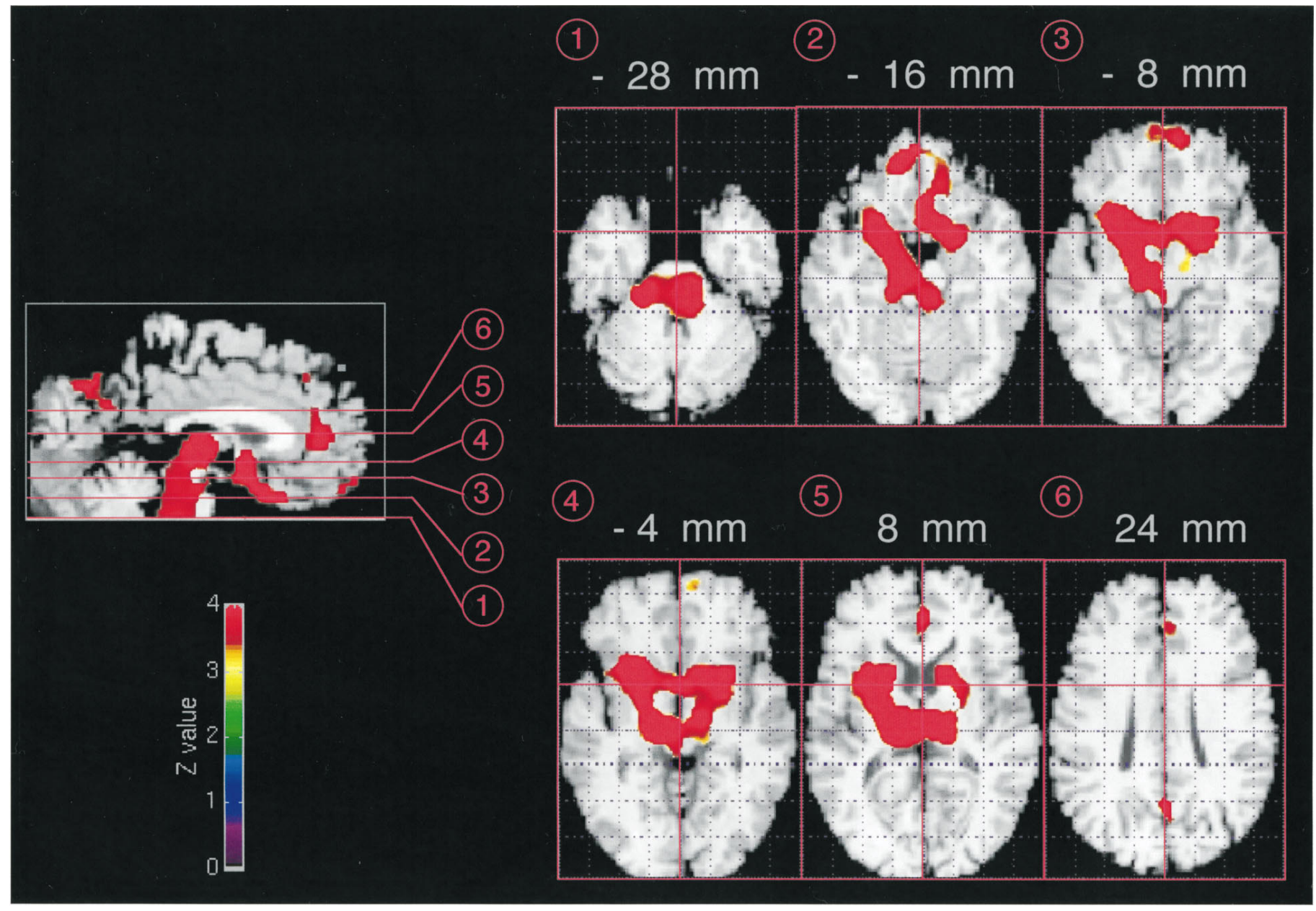

Figure 1. Midsagittal and transverse sections showing brain areas where activity showed a significant negative correlation with SWS. Functional PET results are displayed at threshold of $Z=3.09\left(p<0.001\right.$, with $\left.p_{\text {corrected }}<0.05\right)$ and superimposed, for anatomical reference, on a T1-weighted MRI scan normalized into the Talairach space. Section numbers on the sagittal section refer to the respective transverse sections from -28 to $24 \mathrm{~mm}$ from the bicommissural plane. See description in the text.

In animal experiments the cortex not only receives synchronous bursts from thalamocortical neurons within spindle or delta frequency range; it also reinforces the synchronization of thalamic oscillations (Steriade et al., 1991) and reorganizes the thalamic delta rhythm to yield the irregular EEG delta activity usually recorded at the scalp (Steriade et al., 1993a). The cortex also seems to be capable of generating a delta rhythm by itself (Villablanca, 1974). Furthermore, the intrinsic properties of cortical neurons and of intracortical circuits generate a slow rhythm that groups thalamically generated rhythms within sequences recurring at low frequencies $(<1 \mathrm{~Hz}$; Steriade et al., 1993c). These processes would not occur homogeneously in the whole cortical mantle and might be modulated differently in frontal cortex (especially its orbitofrontal portion) than in other parts of the brain. Accordingly, human sleep EEG data indicate that the delta power predominates in frontal areas during SWS (Zeitlhofer et al., 1993).

\section{Functional significance of ventromedial frontal deactivation during SWS}

It recently has been suggested that the spatially widespread and temporally coherent neuronal activity occurring during SWS could be used to reorganize cortical networks throughout the cerebrum (Steriade et al., 1993b). Our results further suggest that these cellular processes might be more marked in orbitofrontal cortex and anterior cingulate gyrus than in the rest of the cortex. If this were the case, one should expect that sleep deprivation would disrupt the functions subtended by these areas during waking.

Orbitofrontal cortex and anterior cingulate cortex (especially BA 24) are implicated in the control of emotions, behavior, and social interactions (Fuster, 1989; Devinsky et al., 1995). Patients with orbitofrontal or anterior cingulate lesions usually present with various clinical signs such as impulsivity, loss of social constraints, bulimia, and distractibility. It is noteworthy that similar signs, such as childish humor (Kollar et al., 1966), disinhibited behavior and irritability (Bliss et al., 1959), distractibility (Norton, 1970), and perseverations (Horne, 1988), likewise are observed after short-term total sleep deprivation in man, the effects of which can be attributed primarily to SWS deprivation (Horne, 1993). Given the role of orbitofrontal cortex and anterior cingulate cortex in the regulation of emotions and behavior, it is also noteworthy that a recent meta-analysis shows that one of the main effects of sleep deprivation in humans is modification of affect (Pilcher and Huffcutt, 1996).

Recently, ventromedial frontal areas, which encompass orbitofrontal and anterior cingulate cortices, have been implicated in decision-making (Bechara et al., 1994). This process 
aims at integrating large numbers of facts, past experience, and calculations to adapt the behavior in the best interest of the individual (Adolphs et al., 1996). Decision-making would rely on the reactivation of "somatic markers," the somatic labels of emotions that usually automatically signal future deleterious or advantageous outcomes of a behavior (Damasio et al., 1990). It is not known whether sleep deprivation rapidly leads to such deficit, although a recent report shows that, after one single night of sleep deprivation, a deficit in making appropriate decisions during "real economic world" simulation is already present (Harrison and Horne, 1996).

Other signs observed after short-term sleep deprivation do not depend on ventromedial frontal areas. For instance, decreased verbal fluency (Friston et al., 1991b) or impaired planning (Baker et al., 1996), tasks known to rely on the dorsolateral prefrontal cortex, rapidly are impaired by sleep deprivation (Horne, 1988). Dorsolateral prefrontal cortex does not show up on our maps, even at lower $Z$ thresholds (up to $p<$ 0.1 , uncorrected). However, we do not know whether use of a larger population would not have revealed the existence of a dorsolateral prefrontal deactivation.

\section{Comments on the deactivation of mediotemporal area and precuneus}

In contrast to frontal areas, neither neurophysiological data nor previous neuroimaging studies nor the psychological effects of sleep or sleep deprivation would have predicted the deactivation of right mediotemporal cortex and precuneus. We critically comment on these results in the following paragraphs.

The interpretation of the mediotemporal deactivation should remain cautious. Indeed, the anatomical localization of the area is difficult. Furthermore, neurophysiological data in animals (Rank, 1973; Chrobak and Buszaki, 1994) and in humans (Freemon and Walter, 1970) indicate the persistence of an important activity in the hippocampal formation during SWS. Finally, sleep periods do not seem to have any significant beneficial effect on the retention of explicit memory material (Smith, 1995).

The precuneus is a cerebral region that recently has received much investigative attention. It has been implicated in visual mental imagery tasks (Kosslyn et al., 1993) and in visual attention paradigms (Corbetta et al., 1993) and may serve as a visual imagery buffer (Fletcher et al., 1995) in memory tasks (Petrides et al., 1993; Shallice et al., 1994). Interestingly, the resting state during $\mathrm{W}$ also is characterized by a significant activation of the precuneus (Andreasen et al., 1995; our own results, not shown). In contrast, precuneus is less active than the rest of the brain during both SWS (present results) and REM sleep (Maquet et al., 1996). In other words, W is characterized by a prominent activity in the neural networks to which precuneus participates (visual imagery in attention and memory tasks). In contrast, in states of decreased vigilance during which consciousness is decreased dramatically or abolished, precuneus is relatively less active. This observation might suggest an active participation of precuneus in conscious processes.

\section{Conclusions}

The distribution of $\mathrm{rCBF}$ is not homogeneous throughout the cerebrum during SWS in man. Blood flow is decreased markedly in central core structures (dorsal pons, mesencephalon, thalamic nuclei, and basal forebrain) because of the cellular mechanisms that lead to the generation and maintenance of slow sleep rhythms.

Within the cortex, among areas where rCBF is decreased maximally during SWS, ventromedial frontal regions are involved during waking, in the regulation of emotion, and in the adaptation of behavior through adequate decision-making. These functions seem to be altered rapidly by sleep deprivation. This is in line with a favorable effect of sleep on cerebral function. Further studies are needed to determine precisely these beneficial influences of sleep on higher cerebral function.

\section{REFERENCES}

Adam K (1980) Sleep as a restorative process and a theory to explain why. In: Adaptive capabilities of the nervous system (McConnel PS, Boer GJ, Romijn HJ, Van de Poll NE, Corner MA, eds), pp 289-305. Amsterdam: Elsevier.

Adolphs R, Tranel D, Bechara A, Damasio H, Damasio AR (1996) Neuropsychological approaches to reasoning and decision-making. In: Neurobiology of decision-making (Damasio AR, Damasio H, Christen Y, eds), pp 157-179. Berlin: Springer.

Andreasen NC, O'Leary DS, Cizadlo T, Arndt S, Rezai K, Watkins GL, Boles Ponto LL, Hichwa RD (1995) Remembering the past: two facets of episodic memory explored with positron emission tomography. Am J Psychiatry 152:1576-1585.

Arndt S, Cizaldo T, O'Leary D, Gold S, Andreasen NC (1996) Normalizing counts and cerebral blood flow intensity in functional imaging studies of the human brain. NeuroImage 3:175-184.

Baker SC, Rogers RD, Owen AM, Frith CD, Dolan RJ, Frackowiak RSJ, Robbins TW (1996) Neural systems engaged by planning: a PET study of the Tower of London task. Neuropsychologia 34:515-526.

Balkin TJ, Wesensten NJ, Braun AR, Berman K, Baldwin P, Stein S, Carson RE, Herscovitch P, Belenky G (1991) Cerebral blood flow as measured by $\mathrm{H}_{2}{ }^{15} \mathrm{O}$ positron emission tomography prior to, during, and following recovery sleep. Sleep Res 20:37.

Bechara A, Damasio AR, Damasio H, Anderson SW (1994) Insensitivity to future consequences following damage to human prefrontal cortex. Cognition 50:7-15.

Berger RJ, Philipps NH (1995) Energy conservation and sleep. Behav Brain Res 69:65-73.

Bliss EL, Clarck LD, West CD (1959) Studies of sleep deprivation. Arch Neurol 81:348-359.

Braun AR, Balkin TJ, Wesensten NJ, Baldwin P, Berman KF, Carson RE, Belenky G, Herscovitch P (1992) Regional cerebral blood flow measured by $\mathrm{H}_{2}{ }^{15} \mathrm{O}$ positron emission tomography (PET) during discrete stages of the human sleep-wake cycle. Neurology 42[Suppl 3]:182.

Buchsbaum MS, Gillin JC, Wu J, Hazlett E, Sicotte N, Dupont RM, Bunney WE (1989) Regional cerebral glucose metabolic rate in human sleep assessed by positron emission tomography. Life Sci 45:1349-1356.

Chrobak JJ, Buszaki G (1994) Selective activation of deep layer (V-VI) retrohippocampal cortical neurons during hippocampal sharp waves in the behaving rat. J Neurosci 14:6160-6170.

Corbetta M, Miezin FM, Shulman GL, Petersen SE (1993) A PET study of visuospatial attention. J Neurosci 13:1202-1226.

Cowan RL, Wilson CJ (1994) Spontaneous firing patterns and axonal projections of single corticostriatal neurons in the rat medial agranular cortex. J Neurophysiol 71:17-32.

Damasio AR, Tranel D, Damasio H (1990) Individuals with sociopathic behavior caused by frontal damage fail to respond autonomically to social stimuli. Behav Brain Res 41:81-94.

Degueldre C, Quaglia L (1992) Performance evaluation of a new wholebody positron tomograph: the ECAT 951/31 R. Proc Int Conf IEEE 14:1831-1833.

Devinsky O, Morrell MJ, Vogt BA (1995) Contributions of anterior cingulate cortex to behaviour. Brain 118:279-306.

Fletcher PC, Frith CD, Baker SC, Shallice T, Frackowiak RSJ, Dolan RJ (1995) The mind's eye-precuneus activation in memory-related imagery. NeuroImage 2:195-200.

Fox PT, Mintun MA (1989) Noninvasive functional brain mapping by change-distribution analysis of averaged PET images of $\mathrm{H}_{2}{ }^{15} \mathrm{O}$ tissue activity. J Nucl Med 30:141-149.

Frackowiak RSJ, Friston K (1994) Functional neuroanatomy of the human brain: positron emission tomography—a new anatomical structure. J Anat 184:211-225.

Freemon FR, Walter RD (1970) Electrical activity of human limbic system during sleep. Compr Psychiatry 11:544-551.

Friston KJ, Frith CD, Liddle PF, Dolan RJ, Lammertsma AA, Frackowiak RSJ (1990) The relationship between global and local changes in PET scans. J Cereb Blood Flow Metab 10:458-466. 
Friston KJ, Frith CD, Liddle PF, Frackowiak RSJ (1991a) Comparing functional (PET) images: the assessment of significant change. J Cereb Blood Flow Metab 11:690-699.

Friston KJ, Frith CD, Liddle PF, Frackowiak RSJ (1991b) Investigating a network model of word generation with positron emission tomography. Proc R Soc Lond [Biol] 244:101-106.

Friston KJ, Worsley KJ, Frackowiak RSJ, Mazziotta JC (1994) Assessing the significance of focal activations using their spatial extent. Hum Brain Mapp 1:210-220.

Friston KJ, Ashburner J, Frith C, Poline JB, Heather J, Frackowiak RSJ (1995a) Spatial realignment and normalization of images. Hum Brain Mapp 2:165-189.

Friston KJ, Holmes AP, Worsley KJ, Poline JB, Frith CD, Frackowiak RSJ (1995b) Statistical parametric maps in functional imaging: a general linear approach. Hum Brain Mapp 2:189-210.

Fuster JM (1989) The prefrontal cortex. Anatomy, physiology, and neuropsychology of the frontal lobe. New York: Raven.

Giuditta A (1985) A sequential hypothesis for the function of sleep. In: Sleep '84 (Koella WP, Rüther E, Schulz H, eds), pp 222-224. Stuttgart: Verlag.

Harrison Y, Horne JA (1996) Performance on a complex frontal lobeoriented task with "real world" significance is impaired following sleep loss. J Sleep Res 5[Suppl 1]:87.

Hetta J, Onoe H, Andersson J, Broman JE, Valind S, Lilja A, Sundin A, Lindström K, Watanabe Y, Langström B (1995) Cerebral blood flow during sleep-a positron emission tomographic (PET) study of regional changes. Sleep Res[A] 24:87.

Horne JA (1988) Sleep loss and "divergent" thinking ability. Sleep 11:528-536.

Horne JA (1993) Human sleep, sleep loss, and behaviour. Implications for the prefrontal cortex and psychiatric disorder. $\mathrm{Br} \mathrm{J}$ Psychiatry 162:413-419.

Ingvar M, Eriksson L, Greitz T, Stone-Elander S, Dahlbom M, Rosenquist G, Af Trampe P, von Euler C (1994) Methodological aspects of brain activation studies: cerebral blood flow determined with $\left[{ }^{15} \mathrm{O}\right]$ butanol and positron emission tomography. J Cereb Blood Flow Metab 14:628-638.

Kennedy C, Gillin JC, Mendelson W, Suda S, Miyaoka M, Ito M, Nakamura RK, Storch FI, Pettigrew K, Mishkin M, Sokoloff L (1980) Loca cerebral glucose utilization in non-rapid eye movement sleep. Nature 297:325-327.

Khateb A, Muhlethaler M, Alonso A, Serafin M, Mainville M, Jones BE (1992) Cholinergic nucleus basalis neurons display the capacity for rhythmic bursting activity mediated by low-threshold calcium spikes Neuroscience 51:489-494.

Kollar EJ, Slater GR, Palmer JO, Docter RF, Mandell AJ (1966) Stress in subjects undergoing sleep deprivation. Psychosom Med 28:101-113.

Kosslyn SM, Alpert NM, Thompson WL, Maljkovic V, Weise SB, Chabris CF, Hamilton SE, Rauch SL, Buonanno FS (1993) Visual mental imagery activates topographically organized visual cortex: PET investigations. J Cognit Neurosci 5:263-287.

Krueger JM, Obal F, Kapas L, Fang J (1995) Brain organization and sleep function. Behav Brain Res 69:177-185.

Madsen PL, Schmidt JF, Wildschiodtz G, Friberg L, Holm S, Vorstrup S, Lassen NL (1991) Cerebral $\mathrm{O}_{2}$ metabolism and cerebral blood flow in humans during deep and rapid-eye-movement sleep. J Appl Physiol 70:2597-2601

Mangold R, Sokoloff L, Conner E, Kleinerman J, Therman PO, Kety SS (1955) The effects of sleep and lack of sleep on the cerebral circulation and metabolism of normal young men. J Clin Invest 34:1092-1100.

Maquet P (1995) Sleep function(s) and cerebral metabolism. Behav Brain Res 69:75-83.

Maquet P, Dive D, Salmon E, Sadzot B, Franco G, Poirrier R, von Franckell R, Franck G (1990) Cerebral glucose utilization during sleep-wake cycle in man determined by positron emission tomography and $\left[{ }^{18} \mathrm{~F}\right] 2$-fluoro-2-deoxy-D-glucose method. Brain Res 513:136-143.

Maquet P, Peters J, Delfiore G, Aerts J, Degueldre C, Fuchs S, Delvaux G, Quaglia L, Luxen A, Franck G (1995) Regional cerebral haemodynamics during slow sleep and paradoxical sleep. Preliminary results of a positron emission tomography (PET) study. Sleep Res [A] 24:89.

Maquet P, Péters JM, Aerts J, Delfiore G, Degueldre C, Luxen A, Franck G (1996) Functional neuroanatomy of human rapid eye movement sleep and dreaming. Nature 383:163-166.

McGinty D, Szymusiak R (1990) Keeping cool: a hypothesis about mechanisms and functions of slow wave sleep. Trends Neurosci 13:480-487.
Meddis R (1977) The sleep instinct. London: Routledge.

Meddis R (1983) The evolution of sleep. In: Sleep mechanisms and functions in humans and animals - an evolutionary perspective (Mayes A, ed), pp 57-106. Wokingham, UK: Van Nostrand Reinhold.

Metherate R, Cox CL, Ashe JH (1992) Cellular bases of neocortical activation: modulation of neuronal oscillations by the nucleus basalis and endogenous acetylcholine. J Neurosci 12:4701-4711.

Mukhametov LM, Supin AY, Lyamin OI (1988) Interhemispheric asymmetry of the EEG during sleep in mammals. In: Neurobiology of sleep-wakefulness cycle (Oniani T, ed), pp 147-159. Tbilisi, Georgian Republic: Metsniereba.

Norton R (1970) The effects of acute sleep deprivation on selective attention. Br J Psychol 61:157-161.

Nunez A (1996) Unit activity of rat basal forebrain neurons: relationship to cortical activity. Neuroscience 72:757-766.

Oldfield RC (1971) The assessment and analysis of handedness: the Edinburgh inventory. Neuropsychologia 9:97-113.

Petrides M, Alivisatos B, Meyer E, Evans AC (1993) Functional activation of the human frontal cortex during the performance of verbal memory tasks. Proc Natl Acad Sci USA 90:878-882.

Pilcher JS, Huffcutt AI (1996) Effects of sleep deprivation on performance: a meta-analysis. Sleep 19:318-326.

Rank JB (1973) Studies on single neurons in dorsal hippocampal formation and septum in unrestrained rats. Part I. Behavioral correlates and firing repertoires. Exp Neurol 42:461-531.

Rechtschaffen A, Kales AA (1968) A manual of standardized terminology, techniques, and scoring system for sleep stages of human subjects. Bethesda, MD: US Department of Health, Education, and Welfare.

Sakai F, Stirling Meyer J, Karacan I, Dermap S, Yamamoto M (1980) Normal human sleep: regional cerebral hemodynamics. Ann Neurol 7:471-478.

Shallice T, Fletcher P, Frith CD, Grasby P, Frackowiak RSJ, Dolan R (1994) Brain regions associated with acquisition and retrieval of verbal episodic memory. Nature 368:633-635.

Smith C (1995) Sleep states and memory processes. Behav Brain Res 69:137-145.

Steriade M, McCarley RW (1990) Brainstem control of wakefulness and sleep. New York: Plenum.

Steriade M, Jones EG, Llinas RR (1990) Thalamic oscillations and signaling. New York: Wiley.

Steriade M, Curro Dossi M, Nunez A (1991) Network modulation of a slow intrinsic oscillation of cat thalamocortical neurons implicated in sleep delta waves: cortically induced synchronization and brainstem cholinergic suppression. J Neurosci 11:3200-3217.

Steriade M, Contreras D, Curro Dossi R, Nunez A (1993a) The slow $(<1 \mathrm{~Hz})$ oscillation in reticular thalamic and thalamocortical neurons: scenario of sleep rhythm generation in interacting thalamic and cortical networks. J Neurosci 13:3284-3299.

Steriade M, McCormick DA, Sejnowski TJ (1993b) Thalamocortical oscillations in the sleeping and aroused brain. Science 262:679-685.

Steriade M, Nunez A, Amzica F (1993c) Intracellular analysis of relations between the slow $(<1 \mathrm{~Hz})$ neocortical oscillation and other sleep rhythms of the electroencephalogram. J Neurosci 13:3266-3283.

Szymusiak R (1995) Magnocellular nuclei of the basal forebrain: substrates of sleep and arousal regulation. Sleep 18:478-500.

Szymusiak R, McGinty D (1986) Sleep-related neuronal discharge in the basal forebrain of cats. Brain Res 370:82-92.

Talairach J, Tournoux P (1988) Co-planar stereotaxic atlas of the human brain. Stuttgart: Thieme-Verlag.

Townsend RE, Prinz PN, Obrist WD (1973) Human cerebral blood flow during sleep and waking. J Appl Physiol 35:620-625.

Villablanca J (1974) Role of the thalamus in sleep control: sleep-wakefulness studies in chronic diencephalic and athalamic cats. In: Basic sleep mechanisms (Petre-Quadens O, Schlag J, eds), pp 51-81. New York: Academic.

Webb WB (1974) Sleep as an adaptive response. Percept Mot Skills 38:1023-1027.

Wilson CJ (1994) Generation of natural firing patterns in neostriatal neurons. In: Progress in brain research, Vol 99, Chemical signalling in the basal ganglia (Arbuthnott GW, Emsson PC, eds), pp 277-297. Amsterdam: Elsevier.

Zeitlhofer J, Anderer P, Obergottsberger S, Schimicek P, Lurger S, Marschnigg E, Saletu B, Deecke L (1993) Topographic mapping of EEG during sleep. Brain Topogr 6:123-129. 